\title{
EDITORIAL
}

\section{The role of Epstein-Barr virus in pleural effusions of unknown aetiology: an interesting clinical perspective}

\author{
E. Martró and V. Ausina
}

$\mathbf{P}$ leural effusion is a relatively common clinical condition that requires a differential diagnosis as it may represent the primary manifestation of certain diseases; however, it is commonly observed as a secondary manifestation or complication of other diseases. Primary causes include cardiac failure, infectious aetiology (75\% bacterial and $25 \%$ viral), and malignancy (mostly lung and breast cancer), while the other diseases comprise pulmonary embolism, liver cirrhosis, subphrenic abscess or pancreatitis [1]. In addition, symptoms associated with pleural effusions, such as cough, dyspnoea and chest pain, are nonspecific. Therefore, the history of the patient, physical findings and laboratory tests are necessary for the clinician to narrow down the differential diagnosis [2].

The cause of pleural effusion may be determined in most cases, depending on clinical presentation, imaging techniques and pleural fluid analysis. Pleural fluid analysis is the most useful test and, together with clinical information, usually allows the diagnosis of pleural effusion in $\sim 75 \%$ of patients [3]. A definite diagnosis can generally be obtained in $\sim 25 \%$ of cases, after finding malignant cells or microorganisms. In $\sim 50 \%$ of cases, only a presumptive diagnosis can be obtained based on clinical impression. After excluding an infection as the cause of the pleural effusion, clinical orientation upon pleural fluid analysis is possible in a greater percentage of patients. In cases where a diagnosis cannot be obtained, observation of the patient, repeated pleural fluid analysis or more invasive procedures may be indicated. Even after invasive procedures, such as thoracoscopy, are used, the cause of the pleural effusion cannot be established in up to $15 \%$ of patients [4].

Thoracocentesis is indicated in all clinically significant pleural effusions of unknown origin and in effusions that do not respond to treatment. Pleural fluid biochemical analysis allows the classification into transudates (caused by imbalances between the hydrostatic and oncotic pressures in the chest) or exudates (due to alterations in local factors involved in pleural fluid accumulation), according to the levels of serum and pleural fluid protein, lactate dehydrogenase and cholesterol. Additionally, nucleated cells, glucose, $\mathrm{pH}$, amylase, cytological examination and immunological markers may be determined in pleural fluid to aid diagnosis [1]. Bacterial culture should be performed in purulent effusions, and the presence of microorganisms, such as mycobacteria, fungi and parasites, should be investigated if there is suspicion [5].

CORRESPONDENCE: V. Ausina, Microbiology Service, Hospital Germans Trias i Pujol, Crta. Del Canyet s/n Badalona, 08916, Spain. Fax: 34 934978895. E-mail: vausina@ns.hugtip.scs.es
Diagnosis of viral effusions is mainly based on clinical information, but serum antibody titres, virus culture or detection of specific antibodies in pleural fluid may also be useful [1]. Amongst viral causes, THIJSEN et al. [6] report, in this issue of the European Respiratory Journal, the detection of Epstein-Barr virus (EBV) DNA in a high percentage of pleural effusions of unknown cause. The authors suggest a possible aetiological contribution of this virus to pleural effusions and describe potential mechanisms involved in EBV reactivation in pleural fluid.

EBV infects $>90 \%$ of the population worldwide and, like other herpes viruses, it is able to establish a lifelong latent infection with intermittent reactivation to lytic replication. EBV is mostly transmitted through saliva, and primary infection usually occurs subclinically in infancy and childhood. However, in industrialised countries, infection may not take place until adolescence or young adulthood, causing infectious mononucleosis in $>50 \%$ of cases. After primary infection, EBV persists in the organism in latently infected memory B-cells with occasional shedding into saliva $[7,8]$. The number of EBV latently infected cells remains stable over years, but may vary among different individuals [9]. EBV viral loads in normal adults (healthy carriers) are usually undetectable, with 0.1-24 latently infected B-cells per million peripheral blood mononuclear cells (PBMC) in the circulation [10] and low numbers of viral genomes per infected cell [11]. However, viral loads may rise up to 5,000-50,000 genomes per million PBMC at diagnosis of EBV-related malignancies, such as Hodgkin's disease, post-transplant lymphoproliferative disease and AIDS-associated lymphoma [12, 13].

Although the virus rarely causes disease in immunocompetent individuals, latent genes are potentially oncogenic and EBV has been associated with a wide variety of lymphoid and epithelial diseases, both benign and malignant. EBV may infect almost any organ and infection might be associated to complications, such as neurological involvement, including Guillain-Barré syndrome, myocarditis or liver failure, amongst others [14, 15]. EBV infection has been found in the pleural space in association with B-cell lymphomas, including primary effusion lymphoma, which is aetiologically linked to human Herpesvirus $8[16,17]$, and phyotorax-associated lymphoma [18]. However, the role of EBV in nonlymphoma pleural effusions has not been extensively studied. Interstitial pneumonitis has been associated with chronic active EBV infection and primary infection, both in children and in adults, and pleural effusion has been observed as a rare complication of EBV infection [19-21]. 
In the interesting article by THIJSEN et al. [6], the authors report a relatively high percentage $(40 \%)$ of EBV positivity in pleural fluid by real-time PCR among patients with pleural effusions. This percentage is even higher (59\%) amongst patients with unexplained effusions. Although patients with a positive PCR result in pleural fluid were significantly more likely to also be positive in serum, 12 out of 18 patients had a PCR-positive result in pleural fluid, but not in serum. Moreover, all three patients with a viral load in pleural fluid $>10,000 \mathrm{geq} \cdot \mathrm{mL}^{-1}$ died within 6 months, while amongst the rest, only 16 out of 57 died. These and other findings led the authors to conclude that EBV could be directly involved in the pathogenesis of pleural effusion.

Even though the percentage of EBV-positive pleural fluids was significantly higher amongst patients with an unexplained pleural effusion diagnosis, EBV DNA was also found in pleural fluids from $15 \%$ of patients with a clear diagnosis of the pleural effusion (patients with transudates, empyema or malignancy). Besides, in patients with low viral loads in pleural fluid, the possibility that EBV DNA came from latently infected B-cells present in the fluid rather than from lytic replication could not be excluded. Therefore, additional information from the patients included in the study by THIJSEN et al. [6] would be valuable to help define the clinical relevance of the presence of EBV in pleural effusions, as suggested below.

Several lines of evidence led THIJSEN et al. [6] to conclude that EBV reactivation could take place locally in pleural fluid: 1) amongst EBV-positive pleural effusions, 12 out of 18 patients had a PCR-positive result in pleural fluid, but not in serum; 2) $50 \%$ showed a PCR-positive result in pleural fluid supernatant suggesting the presence of cell-free virus; and 3) two of the patients with a viral load $>10,000 \mathrm{geq} \cdot \mathrm{mL}^{-1}$ of pleural fluid died of unexplained interstitial pneumonia. Even though centrifugation to separate cells from supernatants was performed to try and minimise cell lysis, as stated by THIJSEN et al. [6], treatment of supernatants with DNase previous to PCR would guarantee that the DNA detected was derived from virus particles and not from rupture of infected cells. All 18 patients with an EBV positive result in pleural fluid, for whom a serum sample was available, showed evidence of having a past infection according to the serological tests used (heterophilic antibodies, immunoglobulin (Ig)M against EBV viral capsid antigen (VCA), IgG against EBV VCA and EBV nuclear antigen (EBNA)). Assessing the presence of EBV early antigenspecific antibodies would be valuable to confirm the possibility of viral reactivation.

The detection of specific antibodies in pleural fluid has been suggested as a marker for the diagnosis of infectious aetiology [1]. In the case of tubercular pleurisy, the detection of lipoarabinomannan antibodies in pleural fluid has been reported as a specific diagnostic tool [22]. Testing pleural fluid from the patients included in the study by THIJSEN et al. [6] for EBV-specific antibodies would give additional information to confirm the role of this virus in pleural effusions.

THIJSEN et al. [6] also assessed viral transcription in pelleted pleural fluid cells through the detection of EBER by in situ hybridisation. All six patients with a viral load
$>1,000 \mathrm{geq} \cdot \mathrm{mL}^{-1}$ and enough cells to perform the assay were negative, probably because the number of infected cells was low. Upon analysis of a second specimen, the patient with a highest viral load in pleural fluid showed EBV positivity in pelleted cells, but no EBNA-2 or latent membrane protein 1 expression was seen. Patterns of latency and viral reactivation could be assessed by means of RT-PCR for latent and lytic transcripts, including the ZEBRA transactivator, DNA polymerase BALF5, or glycoprotein BLLF1 [23]. This technique is usually more sensitive than in situ hybridisation for the detection of viral transcripts.

Viral loads in pleural fluid were relatively low in most patients $\left(62 \%\right.$ were $36-1,000 \mathrm{geq} \cdot \mathrm{mL}^{-1}$; overall median was $\left.454 \mathrm{geq} \cdot \mathrm{mL}^{-1}\right)$. Whilst highest values probably reflected active Epstein-Barr virus replication in pleural fluid, the meaning of intermediate values is difficult to establish. Thus, the motivating work by THIJSEN et al. [6] leads the way for additional studies using quantitative PCR in patients with explained and unexplained pleural effusions to establish a cut-off for clinical relevance of Epstein-Barr virus viral load in pleural fluid. Although there are no formal guidelines about how to proceed with the evaluation of pleural effusions of unknown cause [4], and in practice most of them turn out to be malignant [2], perhaps Epstein-Barr virus infection or reactivation should be included in the differential diagnosis in these cases.

\section{REFERENCES}

1 Loddenkemper R. Pleural Effusion. In: Albert RK, Spiro SG, Jett JR, eds. Clinical Respiratory Medicine. 2nd Edn. Mosby Inc., Philadelphia, 2004; pp. 723-733.

2 Rahman NM, Chapman SJ, Davies RJ. Pleural effusion: a structured approach to care. Br Med Bull 2005; 72: 31-47.

3 Collins TR, Sahn SA. Thoracocentesis. Clinical value, complications, technical problems, and patient experience. Chest 1987; 91: 817-822.

4 Light RW. Clinical practice. Pleural effusion. N Engl J Med 2002; 346: 1971-1977.

5 Light RW. Diagnostic approach in a patient with pleural effusion. Eur Respir Mon 2002; 22: 131-145.

6 Thijsen SFT, Luderer R, van Gorp JMH, Oudejans SJG, Bossink AWJ. A possible role for Epstein-Barr virus in the pathogenesis of pleural effusion. Eur Respir J 2005; 26: 662-666.

7 Babcock GJ, Decker LL, Volk M, Thorley-Lawson DA. EBV persistence in memory B cells in vivo. Immunity 1998; 9: 395-404.

8 Miyashita EM, Yang B, Babcock GJ, Thorley-Lawson DA. Identification of the site of Epstein-Barr virus persistence in vivo as a resting B cell. J Virol 1997; 71: 4882-4891.

9 Wagner HJ, Bein G, Bitsch A, Kirchner H. Detection and quantification of latently infected $B$ lymphocytes in Epstein-Barr virus-seropositive, healthy individuals by polymerase chain reaction. J Clin Microbiol 1992; 30: 2826-2829.

10 Yang J, Tao Q, Flinn IW, et al. Characterization of EpsteinBarr virus-infected B cells in patients with posttransplantation lymphoproliferative disease: disappearance after rituximab therapy does not predict clinical response. Blood 2000; 96: 4055-4063. 
11 Miyashita EM, Yang B, Lam KM, Crawford DH, ThorleyLawson DA. A novel form of Epstein-Barr virus latency in normal B cells in vivo. Cell 1995; 80: 593-601.

12 Rowe DT, Qu L, Reyes J, et al. Use of quantitative competitive PCR to measure Epstein-Barr virus genome load in the peripheral blood of pediatric transplant patients with lymphoproliferative disorders. I Clin Microbiol 1997; 35: 1612-1615.

13 Fan H, Gulley ML. Epstein-Barr viral load measurement as a marker of EBV-related disease. Mol Diagn 2001; 6: 279-289.

14 Crawford DH. Biology and disease associations of EpsteinBarr virus. Philos Trans R Soc Lond B Biol Sci 2001; 356: 461-473.

15 Macsween KF, Crawford DH. Epstein-Barr virus - recent advances. Lancet Infect Dis 2003; 3: 131-140.

16 Cesarman E, Chang Y, Moore PS, Said JW, Knowles DM. Kaposi's sarcoma-associated herpesvirus-like DNA sequences in AIDS-related body-cavity-based lymphomas. $N$ Engl J Med 1995; 332: 1186-1191.

17 Renne R, Zhong W, Herndier B, et al. Lytic growth of Kaposi's sarcoma-associated herpesvirus (human herpesvirus 8) in culture. Nat Med 1996; 2: 342-346.
18 Androulaki A, Drakos E, Hatzianastassiou D, et al. Pyothorax-associated lymphoma (PAL): a western case with marked angiocentricity and review of the literature. Histopathology 2004; 44: 69-76.

19 Cloney DL, Kugler JA, Donowitz LG, Lohr JA. Infectious mononucleosis with pleural effusion. South Med J 1988; 81: 1441-1442.

20 Kimura $\mathrm{H}$, Hoshino $\mathrm{Y}$, Kanegane $\mathrm{H}$, et al. Clinical and virologic characteristics of chronic active Epstein-Barr virus infection. Blood 2001; 98: 280-286.

21 Chen J, Konstantinopoulos PA, Satyal S, Telonis J, Blair DC. Just another simple case of infectious mononucleosis? Lancet 2003; 361: 1182.

22 Yokoyama T, Rikimaru T, Kinoshita T, Kamimura T, Oshita Y, Aizawa H. Clinical utility of lipoarabinomannan antibody in pleural fluid for the diagnosis of tuberculous pleurisy. J Infect Chemother 2005; 11: 81-83.

23 Weinberger B, Plentz A, Weinberger KM, Hahn J, Holler E, Jilg W. Quantitation of Epstein-Barr virus mRNA using reverse transcription and real-time PCR. J Med Virol 2004; 74: 612-618. 